\title{
Evolution Game Analysis of Information Sharing Behavior between Supply Chain Members
}

\author{
Kan Yang ${ }^{1, a}$,Shuangliang $\operatorname{Tian}^{1, b^{*}}$, Xiahong Cai $^{1, c}$, Susu Jiao ${ }^{1, d}$ \\ 1 Northwest university for nationalities, mathematics and computer institute, Lanzhou,China

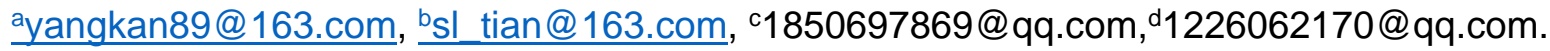

Key Words: Information Sharing; Evolution Game; Information Internalization Innovation Ability

\begin{abstract}
In this paper, we use the idea and method of evolutionary game to construct the asymmetric game problem information sharing in Stackelberg model, which is dominated by the manufacturer.The results show that the dynamic evolution of the system is not stable. The success or failure of information sharing with the manufacturer and retailer is related to their the initial strategic state and internalization innovation capabilities, respectively.
\end{abstract}

\section{Introduction}

Information sharing among supply chain members is often considered to be the basis for supply chain management and critical to the performance of the entire supply chain.Supply chain information sharing is an important method of supply chain coordination,which not only can establish a relatively stable cooperative relationship between supply chain partners,but also effectively restrain the bullwhip effect[1],improve the profit of the whole supply chain and decrease the transaction cost of supply chain members.

In the supply chain,there are a variety of information need to be shared, including material information, inventory information, resource information,order information and planning information and so on,,but the supply chain members generally only consider their own interests, it is difficult to share some information.Simultaneously, supply chain members grasp the information quantity of the market is not the same, which will lead to information asymmetry phenomenon in the supply chain.In order to overcome the information asymmetry in the supply chain and improve the level of information sharing, a large number of literature from different views information sharing research and analysis on the supply chain,such as impact of factors and effect in information sharing $[2,3,4]$.There are also scholars research this question from the incentive mechanism, cooperation and risk $[5,6,7,8]$.

In this paper,we consider the dominant manufacturer Stackelberg information sharing model asymmetric game problem and constructed between supply chain members through information sharing evolutionary game model.The conclusion of this paper can provide scientific and rational theoretical basis and practical guidance for the decision-making of cooperative activities and information sharing between manufacturers and retailers.

\section{Basic assumptions and evolutionary game model}

Basic assumptions. We consider the manufacturer dominates Stackelberg information sharing model in two main game asymmetric game between manufacturers and retailers (A and B), because they are bounded rationality,it is difficult to determine whether their decisions can make their own interests maximize, so they may take a shared or not shared strategy.In order to study the game relations between two participants, we use the relevant parameters and models in reference [9] to make the following assumptions: $S_{i}$ represents information absorptive capacity of participants, $I_{i}$ represents the information sharing amount of participants, $R_{i}$ represents gains after information sharing, $P_{i}$ represents information internalization innovation ability of participants( $i=A, B) . T$ represents retailers are penalized after "hitchhiking" (because manufacturer was dominate, so manufacturer have the ability to punish retailer). 
According to the above basic assumptions and game theory[10],we can determine the supply chain game between the manufacturer and the retailer pay off matrix as shown in table 1.

Table 1 Pay off matrix of general model

\begin{tabular}{|c|c|c|c|}
\hline \multirow{4}{*}{$\begin{array}{l}\text { Manufacturer } \\
\text { (A) }\end{array}$} & \multicolumn{3}{|c|}{ Retailer (B) } \\
\hline & & Share & Not Share \\
\hline & Share & $\mathrm{A}_{11}, \mathrm{~B}_{11}$ & $\mathrm{~A}_{12}, \mathrm{~B}_{12}$ \\
\hline & Not Share & $\mathrm{A}_{21}, \mathrm{~B}_{21}$ & $\mathrm{~A}_{21}, \mathrm{~B}_{21}$ \\
\hline
\end{tabular}

\section{Replicate dynamic equations}

According to the replicate dynamic equations of the theory[11],assumptions the probability of the manufacturer group A adopting the information sharing strategy is $\mathrm{x}$ and not sharing strategy is $1-x$, the probability of the retailer group B adopting the information sharing strategy is $y$ and not sharing strategy is $1-y$.By two groups replicator dynamic equation, the following automated system:

$$
\frac{\dot{p}}{p}=e^{1} \cdot A Q^{T}-P \cdot A Q^{T}, \quad \frac{\dot{q}}{q}=e^{1} \cdot B P^{T}-Q \cdot B P^{T}
$$

Then, $e^{1}=(1,0)$ represents unit vector, $P=(x, 1-x)$ represents a mixed strategy of information sharing and not sharing to manufacturer group $\mathrm{A}, Q=(y, 1-y)$ represents a mixed strategy of information sharing and not sharing to manufacturer group $\mathrm{B}$.

Thus, the dynamics equations for the manufacturer and retailer population systems can be derived:

$$
\left\{\begin{array}{l}
\dot{p}=x(1-x)\left(y R_{A}-P_{B} I_{A}\right) \\
\dot{q}=y(1-y)\left[\left(x\left(R_{B}+T\right)-P_{A} I_{B}\right]\right.
\end{array}\right.
$$

\section{Evolutionary stability strategy and model analysis}

According to evolutionary game theory[12], at the plane $h=\{(p, q) 0 \leq p, q \leq 1\}$, there are five equilibrium point in system (1): $O(0,0), A(0,1), B(1,0), C(1,1), D\left(D_{x}, D_{y}\right), D_{x}=P_{A} I_{B} / R_{B}+T$, $D_{y}=P_{B} I_{A} / R_{A}$. The numerical used to calculate the final results of the dynamic evolution of the system in benefits outweigh risks scenarios by MATLAB12.0.The abscissa represents the probability that A chooses the information sharing strategy,and the vertical axis represents the probability that B chooses the information sharing strategy,as shown in Figure 1

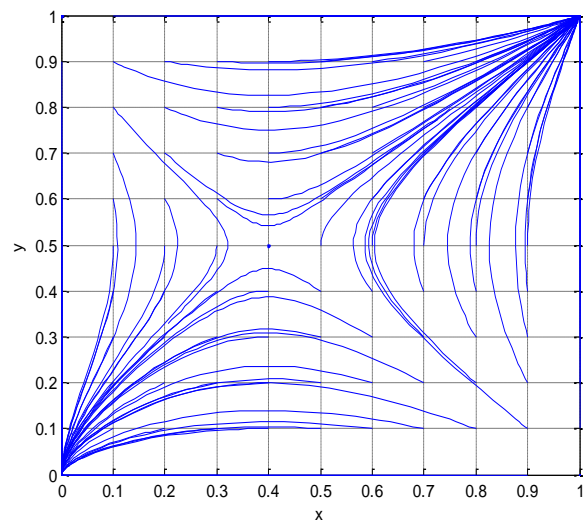

Figure 1 Evolution of the dynamic model

From figure 1 ,we can know that dynamic model have two revolutionary stable strategy(ESS) $O(0,0)$ and $C(1,1)$,respectively.This means that through continuous learning and strategy adjustment, 
even if the manufacturers and retailers to take information sharing strategy will bring more revenue, the two sides may also not take sharing strategy. However, the final dynamic evolution of the system to which the stability point depends on the initial state of the location and proportion of benefits-risk.

\section{Summary}

This paper studies the problem of asymmetric game manufacturers dominated Stackelberg model of information sharing. The results show that the dynamic evolution of the system is not stable. The stable point to which the system eventually evolves depends on the initial strategic state between manufacturer and retailer and internalization innovation capabilities, respectively.

\section{Acknowledgements}

This work was financially supported by State Ethnic Affairs Commission of China (No.12XBZ006),Social Science Planning Project in Gansu Province (No.13YD031),State Ethnic Affairs Commission of China (No.14XBZ018) and Innovative Team Subsidize of Northwest University for Nationalities.

\section{References}

[1] Lee, Hau L., V. Padmanabhan, and S. Whang. "Information Distortion in a Supply Chain: The Bullwhip Effect." Management Science50.4(1997):1875-1886.

[2] Fei, YE. "Relationship among Influential Factors and Level of Information Sharing and Enterprise Performance in Supply Chains."Chinese Journal of Management 6.6(2009):743-750.(In Chinese)

[3] Berger, Paul D. "Vertical Cooperative Advertising Ventures." Journal of Marketing Research9.3 (1972):309-312.

[4] Yan, Ruiliang, and Z. Pei. "Information asymmetry, pricing strategy and firm's performance in the retailer-multi-channel manufacturer supply chain." Journal of Product \& Brand Management 19.1(2011):61-66.

[5] Zhou, Xiongwei, et al. "A Partial Information Sharing Incentive Pricing Model with Demand Uncertainty in Dual-Channel Supply Chain."Przeglad Elektrotechniczny 88.9(2012):204-208.

[6] Jiang-Hua, W. U., and X. Zhai. "Effects of Information Sharing on Cooperative Advertising in A Supply Chain: A Game Theoretic Approach."Chinese Journal of Management Science (2012).(In Chinese)

[7] Lei, Yang, J. I. Jing-Na, and Z. Y. Zhang. "Research on cooperative advertising decisions in a dual-channel supply chain under asymmetric demand information."Control \& Decision 30,12(2015):2285-2292.(In Chinese)

[8] Wang, Wen Li, and Y. W. Xue. "Simulating Risk of Information Sharing of Node Entities in Supply Chain Complex Network." Journal of System Simulation 21,19(2009):6276-6279.

[9] Ozkan-Canbolat, Ela, and A. Beraha. "Evolutionary knowledge games in social networks. " Journal of Business Research 69.5(2016):1807-1811.

[10] Zhiyu Xie, Economic Game Theory(Third Edition)[M]. ShangHai:Fudan University Press,200 7.(In Chinese)

[11] Hofbauer, J., P. Schuster, and K. Sigmund. "A note on evolutionary stable strategies and game dynamics. " Journal of Theoretical Biology81.3(1979):609-12. 
[12] Winter, Sidney G., and R. R. Nelson. An evolutionary theory of economic change /. An evolutionary theory of economic change. Belknap Press of Harvard University Press, 1982. 